\title{
Detlev Lück
}

\section{Walking the tightrope}

\section{Combining family life, career and job mobility ${ }^{1}$}

\section{Drahtseilakte \\ Vereinbarkeit von Familie, Beruf und beruflicher Mobilität}

\begin{abstract}
:
The article examines the ways in which job mobility affects the relationship between dual careers and parenthood and the ability of couples to realise both. Based on survey data from the project Job Mobilities and Family Lives in Europe for six countries (Germany, France, Spain, Poland, Switzerland, Belgium), bivariate analyses compare ratios of couples with children and/or one or two careers between couples confronted with job mobility in the husband's or wife's job and those who have no such mobility. Multivariate analyses test the influence of job mobility and other relevant circumstances on female employment as well as on having children. Indicators measuring respondents' subjective evaluation of the influences are reviewed to confirm the results. The results suggest that couples tend to be childless rather than give up one partner's job if the two goals are incompatible. Job mobility, as with other unfavourable circumstances, reduces the ability of couples to combine both, and this ability is much more reduced if the woman is job mobile than if the man is. In addition, national context matters for level of compatibility and for strength of effects.
\end{abstract}

\section{Zusammenfassung:}

Der Artikel untersucht den Einfluss beruflich bedingter Mobilität auf das Verhältnis von Doppelverdienern und Elternschaft und auf die Fähigkeit von Paaren, beides zu realisieren. Anhand von Umfragedaten des Projektes Job Mobilities and Family Lives in Europe für sechs Länder (Deutschland, Frankreich, Spanien, Polen, Schweiz, Belgien) vergleichen bivariate Analysen Paare, die entweder durch den Beruf des Mannes oder den der Frau mit Mobilität konfrontiert sind, mit Paaren, die nicht davon betroffen sind, hinsichtlich der Anteile von Eltern, von Ein- und von Doppelverdiener-Paaren. Multivariate Analysen testen den Einfluss von beruflicher Mobilität und anderen relevanten Bedingungen auf die Erwerbstätigkeit von Frauen sowie auf Elternschaft. Indikatoren werden gesichtet, die die Beurteilung der Befragten erfassen, um die Befunde zu erhärten. Der Artikel kommt zu dem Schluss, dass Paare eher kinderlos bleiben als eine der beiden Erwerbstätigkeiten aufzugeben, wenn beides nicht miteinander vereinbar ist. Ähnlich wie andere nachteilige Umstände vermindert berufliche Mobilität die Fähigkeit von Paaren, beides zu vereinbaren. Wenn die Frau beruflich mobil ist, ist der Effekt weitaus stärker, als wenn der Mann mobil ist. Auch der nationale Kontext macht einen Unterschied: sowohl für den Grad der Vereinbarkeit im Allgemeinen wie auch für die Stärke der Effekte.

1 I would like to thank Silvia Ruppenthal for helpful comments! 
Key words: job mobility, spatial mobility, female employment, parenthood, balancing work and family lives
Schlagwörter: berufliche Mobilität, räumliche Mobilität, Frauenerwerbstätigkeit, Elternschaft, Vereinbarkeit von Familie und Beruf

Combining paid work with family life or a job career with a family career is, in general, a challenge. This difficult relationship is being studied under the broad headline of worklife or, more precise, work-family issues. Challenges can be studied on two levels, which I want to refer to as compatibility and work-family balance. The focus on compatibility asks whether or not people who wish to have children and a job are capable of realising both. This question, formulated from an individual perspective, is a challenge in contemporary societies, predominantly for women. From a couple's perspective, the question is whether or not a two-career household and parenthood can be realised, assuming that both partners hope to do so. The focus on the work-family balance assumes that people have a job and a family and asks whether or not people are able to invest enough time and energy into both spheres to meet the respective goals and role expectations in a satisfying way. Both kinds of challenges shall be subsumed by the term work-family conflicts. The normative concern that motivates this kind of research is that career jobs are demanding more resources than people are able to invest without neglecting their family lives.

Empirical results often confirm this concern. However, effects vary, of course, according to diverse circumstances, such as the work situation, national context, or gender (Schieman et al. 2003; Schiemann/Glavin 2008; Voydanoff 2004; Gareis et al. 2003; Crompton/Lyonette 2006; Hill et al. 2004). ${ }^{2}$ There may be various consequences: If parents feel unable to invest enough time and energy into their families, they will perceive role conflicts. They may also suffer from stress and their partnership quality, as well as the relationship with their children, may sustain damage. If childless couples perceive the two spheres as being incompatible, they may postpone their family plans or remain childless. Alternatively, if people refuse to cut back on their family investments, they may run into conflicts at work or even feel the need to reduce or interrupt their job career. This is a prioritisation that mostly women make (Maume 2006; Schiemann/Glavin 2008; Reynolds 2005; Gareis et al. 2003). On the macro level, low and decreasing fertility rates and increasing rates of separation and divorce, as well as low employment rates among mothers, may be the consequences. In many European countries, there are low birth rates and high and increasing numbers of couples that remain childless, especially among dualincome couples and among highly educated individuals (Huinink 2009; Frejka/Sobotka 2008; Dorbritz 2000). Divorce rates have also been increasing (Andersson 2003; Höpflinger/Fux 2007). In some countries more than in others, women still tend to leave the labour market after the first child is born (Lück 2009; Schulz/Blossfeld 2006). These observations could be interpreted as the effects of low or even decreasing compatibility.

There are several explanations why compatibility, in fact, could be decreasing. One reason is the increasing labour market participation of women. Between the early 1960s and today, the standard female life course has been transformed from that of a full-time mother and housewife concept to the pattern of steady employment, even with varying

2 It is also noted that people may feel overcharged by their family's demands and escape from stress at home by working extra hours (Hochschild 1997). 
speed and timing in various European societies (Lück 2009). This change is a main reason why work-family conflicts occur in their contemporary form at all (cp. following section). A second reason is attributed to a change in the social construction of parenthood. In some European societies, such as West Germany, expectations regarding what parents need to offer their children in order to be good parents have become much more demanding, while public support for parenting remains scant (Schneider 2002). A third reason is a change in the organisation of paid work. As third- and fourth-sector jobs (i.e., service and knowledge-based positions) are being held by more and more people, work contracts are often time-limited and bound to project funding (Blossfeld et al. 2008) and work time is typically organised flexibly, in the sense that work requirements cause unforeseen overtime. Work time expands (for those who have work, as long as they have work) and becomes less predictable (Hielscher 2003).

All of these processes and others have the consequence that men and especially women are required to invest more time and energy into parenting as well as into a successful job career. At the same time, structural support for parenting in many European countries has not increased in a comparable way. Public childcare is not available for all children, especially those who are very young, in all countries. The hours that children are cared for in kindergartens or schools are often inflexible and too short for both parents to maintain a full-time job. The work hours are often inflexible in a way that the employee cannot adjust them according to his or her needs; instead they are rather flexible in a way that the employer or the customer can do that. There are hardly institutionalised solutions for taking care of children during school vacations. There is also a lack of role models for successfully combining a job and a family career.

One aspect that may also be an important reason for decreasing compatibility has been overlooked for most of the time: professional career-related spatial mobility requirements. The labour markets in contemporary economies do not only demand flexibility in terms of time, but often also in terms of space. A large share of employees in Europe is affected by mobility, and their share has been increasing (Lück/Schneider in this issue; Lück/Ruppenthal 2010). Partly it is the occupation itself that involves travel, more often it is a large distance between home and the workplace that is caused, for example, by a job change or by two distant workplaces of two employed partners. Workers who are spatially mobile for the job invest extra time and energy into this mobility. These resources are lost for both the job and family life. Therefore, mobility should intensify work-family conflicts.

Does job-related spatial mobility decrease compatibility? In what way does it affect the relationship between career jobs and family lives? Does it foster childlessness or, instead, does it lead to more discontinuous career jobs? These questions are discussed in the following. The focus is rather on (in)compatibility - the more fundamental category of work-family conflicts about whether or not career ambitions and family plans can be realised at all - than on "balancing" problems, such as how parents manage a career and children in everyday life. Before searching for answers to these questions, a short historical-theoretical reflection shall clarify where and how to look for them. 


\section{Reflection about the history of work-family relationships, concluding in a methodological remark}

The relationship between professional work and family life has always presented a challenge. However, the conflict was not always a topic, partly because priorities were clear and partly because the distinction between the two spheres was not made. In the following, this history is outlined by describing three ideal type stages of work-family relationships. They rather represent normative concepts, not necessarily solutions that were put into practice by most people. They correspond to three ideal type stages of societal development: the agricultural, the industrial, and the post-industrial society.

In pre-modern agricultural societies, at least for a large majority of people, the family and other non-related household members were a community in which not only household duties and reproduction, but also production, took place. If it is possible to use these terms in this context at all, "professional work" - mainly farming or craft - was done within the household. It was not perceived as competing with "family life;" instead, it was a main part of it. A distinction between the two spheres was not made, and work-family conflicts were not addressed as such.

Conflicts were also not visible because the expectations were very uneven and priorities were clear. The economic survival of the household was unsecure, so that the requirements of the kind of work that provided the economic survival had a much higher priority than the education of the children, the quality of family relationships, or anything that today would be regarded as "family life." "Work life" had the first priority, in terms of compatibility and in terms of work-family balance. Priorities in terms of compatibility were visible in the restrictions for marriage and parenthood: Those who did not have the means to provide for a family were not allowed to have one. Parenthood was allowed only within marriage, and the allowance for marriage was given to farmers with their own land or craftsmen with their own business. Priorities, in terms of work-family balance, were visible in social expectations and norms. In the Middle Ages, childhood was not perceived as a life course phase that contained its own needs. Most expectations towards parenthood that seem to be self-evident today were not existent. Children were not so much demanding their parents' time and energy, competing with economic needs for resources, but rather an additional resource that was invested into the economic survival of the household. Everybody who was able had to participate in "professional work." Also, children were often sent away by their parents to work as maids or farm labourers in a different household where they were more needed.

By today's standards, one could say that the work-family balance was quite out of balance in pre-industrial societies, with "work life" demanding a maximum share of all available resources. Compatibility was solved in a similarly one-sided manner, with parenthood being restricted to those heads of a household who owned a farm or a crafts business and who had use for children as labour. However, people did not perceive this imbalance as such because professional work and family life were not separated and because the expectations regarding a family life beyond these professional activities were low (Mitterauer/Sieder 1984; Gestrich 2003).

The separation of "work life" and "family life" developed within the industrial society. With industrial production replacing craft and farming as the way of making a living, for the 
larger part of societies, the work place changed from an individual's own household to the factory. The household members were not all involved as a group in the same process or place of production. This way work life and family life became distinguishable and their relationship antagonistic. A division of work between family members became the new normative concept of organising the compatibility of the two spheres, with the male breadwinner and female homemaker model as a normative ideal. (The ideal was, however, realised by the bourgeoisie rather than by the working class, where women needed to contribute to the household income. Only in roughly two decades after World War II were most couples able to put this ideal into practice.) The spatial separation of home and work place - an early form of introducing job mobility to large parts of the work force - made a division of responsibilities seem necessary. What occasionally made it possible was the fact that, in industrial production, a single household member was - sometimes - able to provide a household income. As a consequence, the expectation arose that the woman should be exempted from industrial work so that she can take care of household requirements.

It has to be emphasised once more that this was, in the late 19th and early 20th centuries, only a normative concept - a postulated idea of how work-family conflicts could and should be solved. And it has to be emphasised that factual solutions to work-family conflicts in practice highly differentiated between social classes. Working class couples in the 19th century have, for example, hardly been able to exempt women from industrial work. Often they have given children away. As in pre-modern societies, the economic survival still had a much higher priority than the fulfilment of family plans or the investment into family needs. Nevertheless, with the idea of "modern" gender roles, as Durkheim or Parsons would call them, serving as a solution to work-family conflicts, ideas and normative expectations regarding "good" parenthood (or, rather, motherhood) were also formulated. Again as a normative concept, family life became more challenging in the early modern society. The 1950s and early 1960s era was the exceptional time span in which all these expectations were actually met. The fact that one generation had finally managed to meet the expectations is probably important in order to understand why norms regarding good parenthood are quite stable today and have increased in recent decades, although the division of gender roles that enabled this generation to do so is losing its suitability (Gestrich 2008; Gestrich 2003; Mitterauer/Sieder 1984; Lück 2009).

In late modernity, in post-industrial societies, the solution that Europe had finally found in the 1950s is questioned by the reorganisation of gender roles. Women are successfully claiming equal rights and delegitimising the "modern" gender roles of early modernity that forced women into economic dependency and that now are called "traditional." Processes of value change and a second wave of individualisation encouraged women to take the freedom of making career choices of their own and to follow their own interests. Partly as a means for independency, partly as a means for self-fulfilment, women decided to achieve advanced educational degrees and seek professional careers of their own. The process is fostered by the transition into post-industrial societies: New jobs in the third and fourth sector and a more flexible organisation of work simplify women's entry into the labour market. At the same time, after the deceleration of the economic expansion in the 1970s, more households are again dependent on a second household income. As a consequence, there is an increasing number of couples in which two partners have a general interest in their own professional careers. With paid work still happening outside of the household, the 
challenge of how to combine the job with a family life is reintroduced into societies. The delegitimisation of patriarchy makes a new solution necessary. What makes it sometimes possible are varying circumstances: in some countries, generous parental leave; in others, generous public childcare facilities or affordable, privately offered childcare services; in the Netherlands, state support for part-time jobs (Lück 2009; Lück/Hofäcker 2008; Gerhards/Hölscher 2003; Lengerer 2004; Pfau-Effinger 1998).

What has not been established yet again is a standard solution. Not only the mentioned national policies or welfare regimes create a variety of solutions. There are also cultural differences that mainly concern the degree by which the former gender role division has disappeared or is still persisting. This creates not only cross-national differences in the solutions to compatibility, but also between social groups within societies. The cultural change from early to late modernity, in many societies, is still in the flow, as is the reorganisation of family policies and welfare regimes, offering various solutions for parents who try to maintain two professional careers. At the same time, economic change creates differing circumstances. Some jobs are offering flexible working times or the option to work at home so that combining job and family becomes easier. More often, jobs demand flexibility in terms of time and place on the employees' side, so that it becomes more difficult for the employee to navigate successfully. As a consequence, the question whether and how work-family conflicts can be solved varies from couple to couple by a set of conditions on the micro, meso, and macro levels, including the hours and the organisation of the work of both partners' jobs, the individual gender role attitudes of the partners, the predominant gender role culture within the society or social environment, and the family policies within the nation or community (Lück 2009).

One can summarise that work-family conflicts are a challenge for contemporary societies because they appear in a new context - in times of post-industrial work life and the postulation of gender equality. In this context, past solutions no longer work and, so far, a juxtaposition of old and various new solutions is visible. New solutions cannot be found by couples alone, but societies as a whole have to establish cultural orientations and infrastructure support. A set of individual and societal, of cultural and structural conditions, has to be coordinated. What could be a timeless pattern is that the necessity to organise economic survival is given a higher priority than realising family plans or living up to expectations within the family context. If this is true, then increasing demands for job mobility, as any increase in the demands of work life, should have visible effects on compatibility, work-family balance, and family life. However, even this rule could change in late modernity as societies could guarantee economic survival through systems of social security.

\section{How to study work-family conflicts in contemporary societies - a sketch for a methodological programme}

The current situation is a challenge for both theory and research. The description and explanation of whether and how work-family conflicts can be solved has to take into account the collection of conditions and solutions mentioned above. Due to a lack of adequate data, this article will not be able to put into practice this postulation in all of its con- 
sequences. However, as a sketch for a methodological programme that may reach beyond the empirical analyses presented here, it shall formulate what ideally would be necessary to control for in an empirical analysis - and to reflect in a theoretical explanation.

For explaining the success in combining job and family in contemporary Europe, at least three fields of circumstances are of major importance:

- Research has to take into account the requirements of both partners' jobs, inasmuch as they limit the ability to take on responsibilities in family work: for example, the work hours, the flexibility in terms of the work hours and work places which the jobs demand, as well as the flexibility that the jobs offer.

- Research has to include gender role attitudes as moderating variables. The orientation towards a male breadwinner model means that the solution of a full-time mother is available and likely to be taken. An undiluted ideal of gender equality implies that two partners share the burden of combining paid work and parenting. A typical contemporary set of gender role orientations means that it is mostly the woman who has to combine these two spheres.

- Research has to reflect the available support for childcare, such as available childcare facilities or extended family networks.

Taking these observations to a higher level of abstraction, three theses can be formulated:

- Explanations have to take into account the micro and macro level (and, ideally, also the meso level). Adequate methods to do this are, for example, context analysis and multi-level analysis. A suitable theory should be a theory of action that includes a micro-macro link, for example, such as Coleman (1986) suggests it.

- Explanations have to take into account structural constraints and opportunities as well as cultural normative constructions. Neither a strict rational choice theory nor a strict theory of social construction is able to capture all probable influences (Lück/ Hofäcker 2008).

- Explanations have to take a couple perspective. In societies in which the gender division is still strong, the men's focus on paid work may be prevalent enough so that analyses could also define women, instead of couples, as units of action. But even then, the male partner's work situation is an important context that needs to be considered.

An additional postulation can be made. It is, however, not specific for this research topic but concerns all research topics in which the direction of causal relationships can be thought reciprocally or in more than one way (i.e., "Is parenthood postponed because of job mobility or is job mobility refused because of parenthood?”): To control the direction of causal effects, longitudinal research design is necessary.

\section{Theory and method}

As previously mentioned, the following analyses are not able to put into practice all of the aforementioned postulations. Given the limitations in available data as well as in space, a slightly simplified model will be used. Analyses do take a couple perspective. They include structural constraints and opportunities, as well as cultural normative constructions. How- 
ever, a longitudinal research design is not possible, and the macro level can only be included arbitrarily.

The analyses are based on survey data of the project "Job Mobilities and Family Lives in Europe” (cp. Lück/Schneider in this issue; Huynen et al. 2008; Huynen et al. 2010). It contains representative data for six European countries (Germany, France, Spain, Switzerland, Poland, and Belgium). Since these are too few countries and because they are not randomly selected, a multi-level analysis is not an option. Instead, country differences will be measured by differentiating descriptive analyses and by inserting country dummy variables into the regression analyses. Given that the survey has individual level data, the couple perspective is constructed by filtering out respondents who have a stable relationship and by using variables that were collected for the respondent as well as for his or her partner analogously. For example, respondents were not only asked whether they were working for pay, but also whether their partner was, so that, depending on the sex of the respondent, the variables "man is working for pay" and "woman is working for pay" can be constructed. A second criterion for selecting respondents is an age within the range of 25 to 39, assuming that this is the age span in which work-family conflicts typically occur and in which family planning, family formation and family life with young children takes place. All in all, 2077 couples are analysed.

Theoretically, the analyses assume that the couple makes common decisions based on rational reflections of the relevant circumstances. Relevant circumstances are those that affect the couple's available resources in terms of time and energy to invest in two job careers and/or parenthood. They include the micro and macro level. For simplification, it is further assumed that the couple has common goals regarding one or two professional careers, as well as towards family plans that it is trying to realise. Work-family conflicts are likely to occur if the couple's goals include two professional careers and children. These goals are, again, shaped by macro- and meso-level cultural contexts through processes such as socialisation and value change.

Methodologically speaking, two indicators for attitudes are available that come close to measuring the couple's orientation towards a dual career or towards a male breadwinner concept, as well as towards the decision to remain childless or become parents. The respondent was asked whether or not he or she agrees that "it is usually better for the children if the man is the main provider and the woman takes care of the home and the family.” This variable is used as a proxy for the woman's career orientation: Those couples in which the respondent fully agrees (as one optional answer on a four point scale) will be excluded from analyses, assuming that the couple follows a male breadwinner role model and, therefore, does not perceive many work-family conflicts. The respondent was also asked whether or not he or she "intends to have a(nother) child within the next three years.” This indicator measures the couples' immediate family plan. It might work as an interaction effect, intensifying the work-family conflict; however, it might even reflect a selection effect by selecting those whose situation is untroubled enough that concrete family planning is realistic. In any case, it is not a decent indicator for measuring whether or not a couple generally wishes to have children in the long run. So, it will not be used for a further limitation of the sample. Instead, it will be arbitrarily assumed that all couples have at least a latent wish to become parents. 
Given the reciprocal complex causal relationships, analyses will not operationalise the successful combination of two professional careers and family life in one indicator. Instead, two separate causal analyses will take the female partner's full-time employment as the dependent variable in a first step. In a second step, the explained variable will be whether or not the couple has children. This allows the ability to determine which of the two goals is more likely to suffer from which unfavourable circumstances. It also allows for the use of female employment and children as explanatory variables in the other model.

The explanatory variables in the models operationalise the aforementioned circumstances that the couple reflects in making a decision. They include both partners' job situations as well as support for childcare. The job situation is operationalised by including work hours, flexibility of working time, the limitation of the work contract, and, of course, by being mobile for the job. Job mobility here is conceptualised as ongoing recurring mobility. It includes daily long-distance commuting, frequent overnight travel, and living in a long-distance relationship, due to job-related reasons (ср. Lück/Schneider in this issue). Residential mobility is not included. The support for childcare may consist of public childcare, grandparents, friends, or paid private support. Aside from public childcare that partly reflects family policies, macro-level conditions are modelled undifferentiated by measuring country differences.

Although work-family conflicts may have many outcomes - for example, the reduction in work hours, a less prestigious job, or an older age at first birth - the analyses here can only focus on a few. Therefore, with the selection of explained variables - the woman's full-time employment and parenthood - the focus is made on the aspect of compatibility. Before approaching the multi-variate models, binary analyses that have a more descriptive character will be presented.

\section{Are mobile couples less successful in solving work-family conflicts?}

The range of combinations of two partners' professional situations, as well as their family circumstances, is complex. A quantitative analysis has to narrow down this range by reducing the complexity to a small set of ideal type forms that, nevertheless, describe a large share of empirical reality. This is accomplished in the following Figure 1 by distinguishing four groups. Dual-earner parents represent those who have managed to combine two full-time jobs and children. If one partner only works part-time (i.e., less than 35 hours per week), the couple is classified as a 1.5 earner. If one partner does not work at all, then the couple is classified as single-earner parents. Under the (again idealised) assumption that the couple would prefer two full jobs, these two categories present one way of cutting back and failing the aspired ideal. ${ }^{3}$ The second way to cut back is by not having children. This solution is represented by the category of childless couples. The small group of couples without any full-time employed partner is excluded from the comparison

3 One could, of course, also assume that couples would rather combine two part-time jobs with parenthood. This, however, will only be true if attractive part-time jobs are available. For these analyses, a simplified general assumption was necessary and, for the studied countries, the assumption of couples that prefer full-time jobs seemed closer to reality. 
as a "residual category" because their situation presumably does not reflect a decision of how to react to incompatibility.

The distribution of couples over these four categories is differentiated according to whether the woman, the man, or neither of the two partners is recurringly mobile for jobrelated reasons. Again, a few cases are excluded from the analyses: Those couples in which both partners are mobile are not enough to calculate a fourth distribution and there is no good reason to merge them with any of the other three.

Comparing the three distributions allows a first, bi-variate impression of the ways in which mobility affects a couple's ability to realise two professional careers and become parents. The larger the white bar, the more couples are successful. The larger the black bar, the more couples have not (yet) managed to have children. The longer the grey bars, the more couples have at least temporarily cut back on one of the professional careers.

Figure 1: Couples' childlessness and number of jobs by job mobility

घhildless couple $\quad \square$ dual earner parents $\quad \square 1.5$ earner parents $\quad \square$ single earner parents

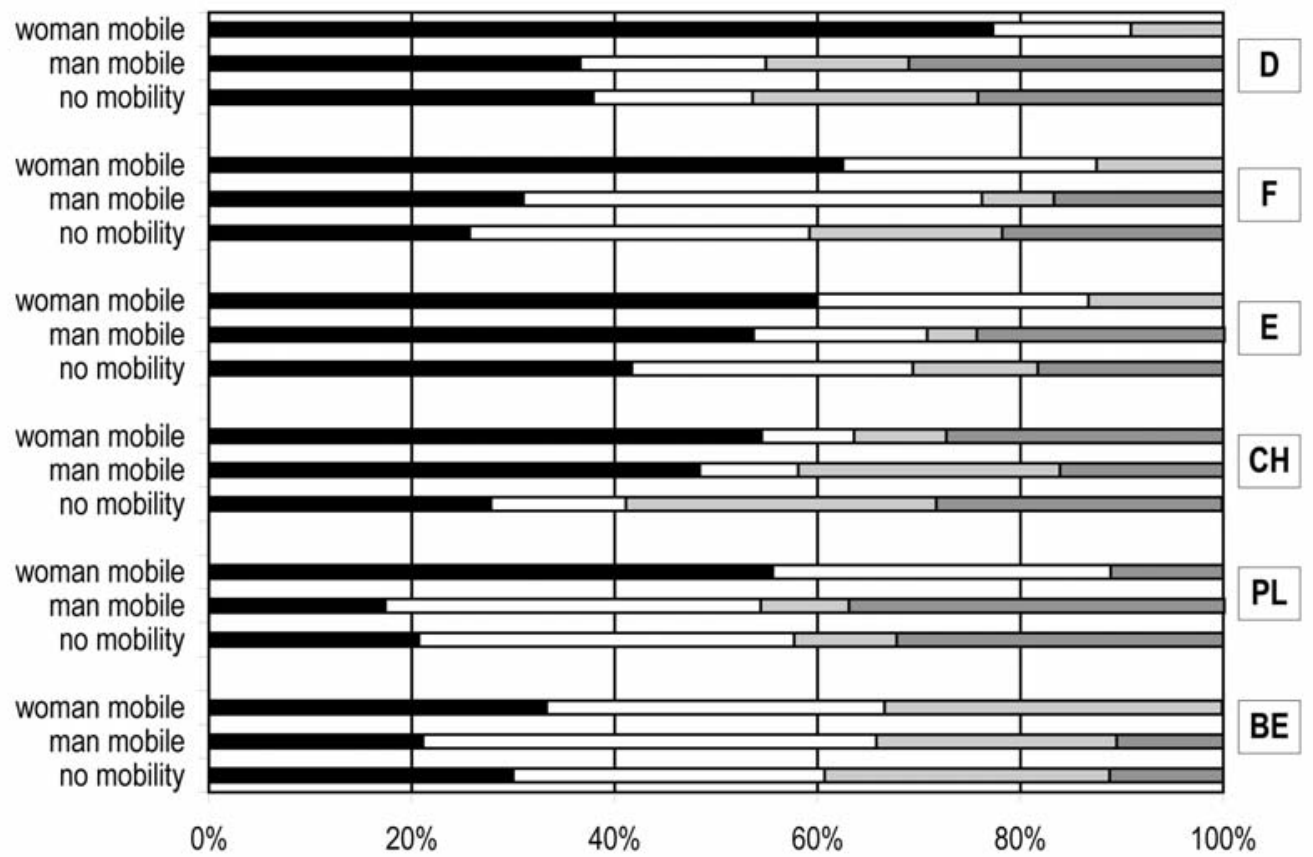

Data: Job Mobilities and Family Lives in Europe. Couples with respondent aged 25 to 39, not fully agreeing that "it is usually better for the children if the man is the main provider and the woman takes care of the home and the family." Comparison of couples in which neither partner, the man, or the woman is recurringly mobile for job-related reasons. Residual categories (e.g., both partners not employed, both partners part-time employed, both partners recurringly mobile) have been excluded from the analysis. Case numbers for couples with a mobile woman are low (n between 30 and 54). Weighted data (w-nation ${ }^{4}$ ).

4 For a documentation of the weights, see Huynen et al. 2010. 
The figure reveals several insights. The most notable result is that couples are seldom single-earner couples if the woman is recurringly mobile. This may seem like a methodological artefact: Anyone who is mobile for job reasons can hardly not be working for pay. So, if one partner is mobile, the statistical likelihood decreases that one partner is not working for pay.

The finding is, however, also an empirical, albeit well-known, result. It becomes visible when we compare couples with mobile women and couples with mobile men. The fact that the man is mobile does not generally decrease the chance that the couple is a singleearner couple. In some countries, the chance even rises. These gender-specific reactions to recurring mobility document the principally persisting (although weakened) gender roles. Men mostly have a strong professional career orientation and might try to integrate a family into their lives as a second priority; women still tend to take on the full responsibility for the children and try, in addition, to have a professional career. In situations of work-family conflicts, men will almost always cut in their family engagement, whereas women, in comparison, will more often cut back in their engagement on the labour market. As a consequence, men do not react to their female partner's job mobility with reducing or interrupting paid work. The couple will be a dual-earner couple and postpone or give up family plans if necessary. Women partly react to their male partner's job mobility by reducing or interrupting paid work, so that the ratio of single-earner couples remains similar to those in which neither partner is mobile.

A second, more surprising, result is that job mobility does not necessarily have visible consequences in terms of a failure in combining two professional careers and children. The white bars, indicating success in that respect, is seldom shorter for couples who experience mobility. They only tend to be shifted to the right side. Job mobility increases the risk of being childless, but not at the cost of dual-earner parent couples; rather, it is at the cost of single-earner couples. The smaller ratio of single-earner couples among mobiles seems, again, self-evident: One partner being mobile for the job implies that this partner is working for pay; this leaves only one (instead of two) partners who might not be in the labour market. Therefore, the couple's likelihood to be a single-earner couple is reduced. And indeed, this result, at least partly, reflects a selection effect. It is caused by the fact that mobility is more likely to occur among dual-earner couples (cp. Collet/Bonnet in this issue; Lück/Ruppenthal 2010). And yet, this is not a methodological artefact. It implies that people who experience job-related mobility make different priorities. They are typically recruited among those who are more job-oriented and would rather postpone or give up family plans. If a couple with different priorities would be confronted with the demand to become mobile, perhaps they would look for a different job - and not appear in the statistics as mobile.

A third result is that the national context matters. The aforementioned patterns are true for all six countries included in the survey. However, the general spread of childlessness and of single-earner couples varies, as does the degree of gender difference in the reaction to mobility. In the figure, France, Belgium, and Poland show a large share of couples who have succeeded in combining two professional careers and parenthood. In Germany and Switzerland, these shares are rather small. This indicates high compatibility in the first group of countries and low compatibility in the latter, which is consistent with known cultural and structural patterns: Germany and Switzerland have a relatively strong expectation regarding the role of the mother as the primary caregiver and little institutional childcare support. France, Poland, and Belgium have culturally established role 
models of mothers working for pay. In France and Belgium, this role model is based on the idea of gender equality and accompanied by good childcare support. In Poland, it is based on the economic need of a second household income (Lück 2009; Lück/Hofäcker 2008). The share of childless couples is generally relatively high in Germany. It is very low in Belgium and Poland. These differences are also consistent with known country-specific patterns (OECD Family Database 2009). Also they mainly reflect (in)compatibility, perhaps with a stronger emphasis on structural support and flexibilisation of paid work.

The effects of recurring mobility on compatibility are especially strong in Germany, France, and Poland. In the same countries, these effects are, at the same time, much more gender-specific than in Spain, Switzerland, or Belgium. In fact, the strong effects are visible, almost only if women are recurringly mobile, yet hardly if men are. This pattern is somewhat surprising and does not conform to most typologies known from the literature. It partly serves as a reminder of the spread of "traditional" versus "modern" gender roles with Germany and, in some ways, also Poland, emphasising differences that are stronger than they are in other countries. This correspondence would be plausible in the sense that effects should be gender-specific, especially where the different responsibilities of men as income providers and women as homemakers are emphasised. However, the numbers for France, Spain, and Switzerland do not neatly fit into this scheme (Lück 2009). A second correspondence may be the spread of mobility forms. In Germany, France, and, in some ways, also in Poland, job-related overnight travel is relatively frequent, whereas the other countries are predominantly characterised by daily long-distance commuting (Lück/Ruppenthal 2010). This may explain the different strengths of effects of recurring mobility on compatibility: In Germany, France, and Poland, recurring mobility stands for overnight absences much more often than in Spain, Switzerland, or Belgium. And it is plausible that overnight travel burdens the compatibility more than daily commutes.

\section{Does mobility have similar effects as other potential causes of work-family conflicts?}

The following Figure 2 shows the effect of recurring mobility of the male or the female partner for the population of all six countries as a whole. The main patterns, which are described above, are visible. This effect is compared to the effects of other circumstances that are likely to affect compatibility: the question of whether or not one of the partners regularly works more than 45 hours per week; has a time-limited work contract (or no contract at all); is "totally or mainly free to choose his or her work hours;" and whether the couple receives any form of external help for childcare or housework. This includes having children at a kindergarten or other childcare facility, having grandparents or friends occasionally providing childcare, as well as private professional help for childcare or for household chores. Again, the bars indicate how many couples, under these circumstances, have one, 1.5, or two jobs and how many are childless. Only for the comparison of whether or not the couple receives childcare support, childless couples are excluded from the comparison.

Results show that these other circumstances have somewhat similar influences as those of recurring job mobility. The effect of having long work hours is practically identical. This 
could be read as a confirmation that a major burden of being mobile for the job is that the travel takes away further couple or family time - just the same as overtime does.

A limited work contract could indicate an insecure economic situation that does not allow long-term binding commitments, such as having children, at least as a statistical tendency. In theory only, from this condition a postponement of parenthood would be a plausible consequence. The analysis confirms such an effect - if it is the man who has the time-limited contract. However, the ratio of childless couples is only marginally higher and the ratio of single-earner couples is higher as well. If the woman's job is uncertain, as previously described, only a selection effect is visible: In that case, the couple is very likely not a single-earner couple, since the woman at least has a work contract. The gender difference is plausible, given that men typically hold the position of the main provider of the household income so that only in their job career does insecurity matter. What is surprising is that the effect is generally rather weak. It seems as if either a limited contract is not perceived as insecurity very often or that the economic situation is considered somewhat insecure anyway, with or without an unlimited work contract.

Figure 2: Couples' childlessness and number of jobs by other circumstances

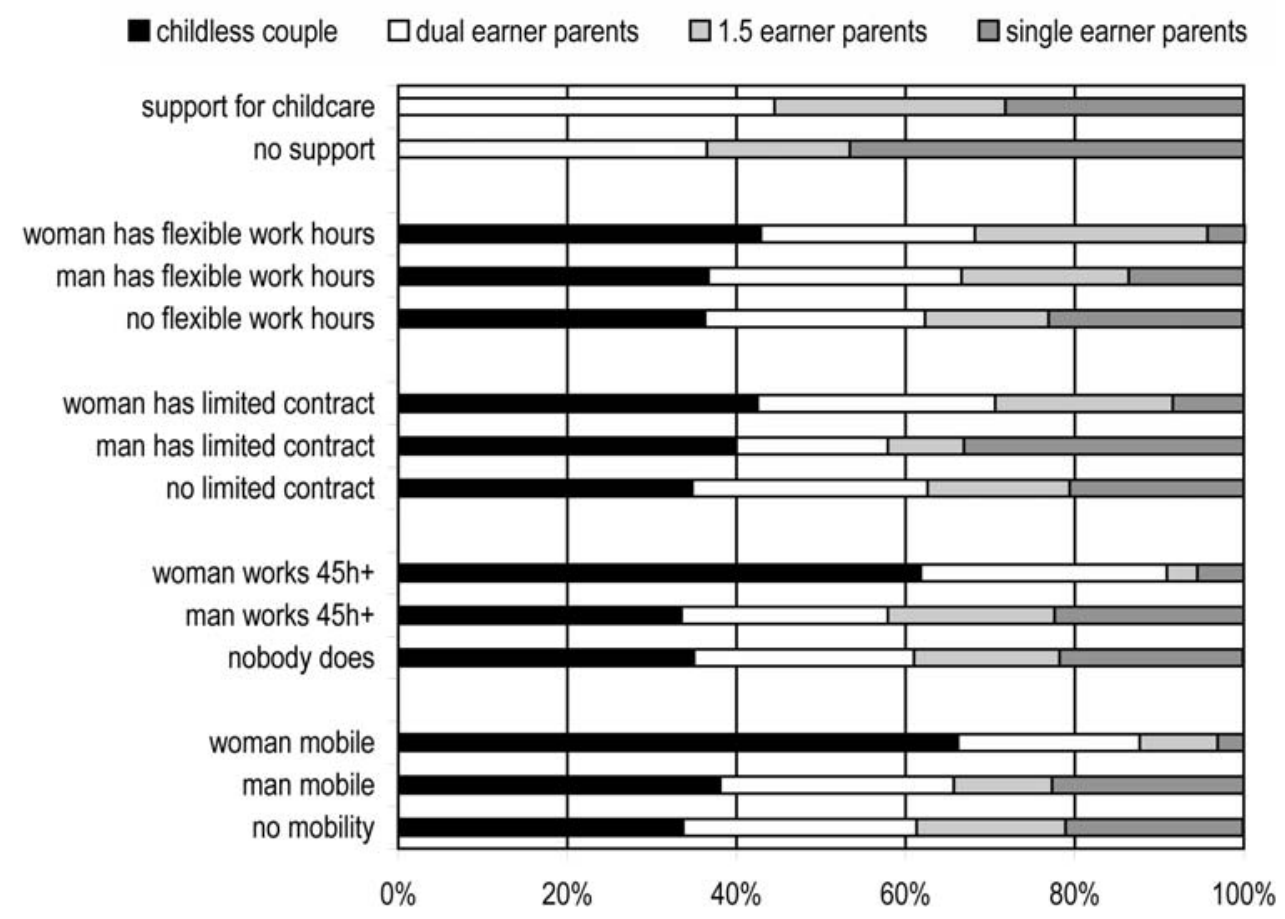

Data: Job Mobilities and Family Lives in Europe. Couples with respondent aged 25 to 39, not fully agreeing that "it is usually better for the children if the man is the main provider and the woman takes care of the home and the family." Comparison of couples in which neither partner, the man, or the woman is recurringly mobile for job-related reasons. Residual categories (e.g., both partners not employed, both partners part-time employed, both partners recurringly mobile) have been excluded from the analysis. The comparison regarding childcare support excludes childless couples. Weighted data (w-proportion). 
The circumstance that partners are able to choose their work hours more or less freely should increase compatibility and support parenthood and family planning. A reciprocal effect would also be plausible with parents negotiating for more freedom in organising their work hours according to their needs. For both reasons, it would be expectable that at least one partner who has this freedom should correlate with the couple that has children. However, this is not the case. There may be a more complex causal relation - perhaps flexible work hours reduce stress for employed parents. A general effect on compatibility and family formation is not visible.

What is plausible is the effect of childcare support. If a couple receives help to care for the children, be it by relatives, friends, privately paid, or public institutions, the partners in this couple have a clearly higher chance of realising two full-time professional careers. The ratio of single-earner parents is significantly lower. However, here again, a causal influence in the opposite direction is also likely: Dual-earner parents organise external support rather than single-earner parents do.

\section{Multivariate analysis, part I: Consequences for family formation}

After describing the distribution of couples regarding parenthood and number of employed partners, as a first bi-variate approach to a causal explanation, a multi-variate analysis shall give answers with more reliable empirical evidence. As previously described, this analysis will be divided into two steps. In the first step, the dependent variable is the question of whether or not the couple has children. In the second step, the dependent variable is whether or not the female partner is working full-time or part-time for pay. This division allows for the inclusion of the woman's job situation (i.e., work hours, flexibility etc.) as explanatory variables in the first step and the family situation in the second step without introducing major biases through selection effects. The two dependent variables are only the two most crucial indicators for the success or failure of combining a job career and a family, indicating that circumstances are supportive in terms of compatibility. Other aspects, such as whether or not the male partner is employed fulltime or the woman is satisfied with her job, will be left for future research.

The model that is presented in Table 1 includes the aforementioned explanatory variables. Additionally, it takes into account whether or not the partners are working for pay at all, whether they work full-time and whether or not they have university degrees. The university degree is a proxy for a support for equal gender roles as well as for job orientation on the woman's side. It is known that women with advanced education are more likely to be in the labour market and to remain childless for a longer amount of time, partly because advanced education implies a high investment in human capital that offers more opportunities on the labour market. It also suggests an increased opportunity cost for interrupting a job career, partly because the academic social milieu transports corresponding values and role models. Age is controlled for in the model because it naturally explains variance, also within the restricted sample of respondents aged 25 to 39.

The overall explanatory power of the model is satisfying (Nagelkerkes $\mathrm{R}^{2}=.401$ ). The standardised regression coefficients confirm several results that were already visible in the bi-variate analyses. 
Table 1: Circumstances fostering couples’ family foundation (logistic regression)

\begin{tabular}{lrc}
\hline & Exp(B) & Sig. \\
\hline man: is working for pay & 1.338 & .314 \\
woman: is working for pay & .709 & .033 \\
man: is working full-time (35h or more) & .950 & .775 \\
woman: is working full-time (35h or more) & .508 & .000 \\
man: is working overtime (45h or more) & 1.224 & .108 \\
woman: is working overtime (45h or more) & .608 & .005 \\
man: is recurringly mobile for the job & .723 & .010 \\
woman: is recurringly mobile for the job & .598 & .001 \\
man: can choose work hours freely & 1.085 & .563 \\
woman: can choose work hours freely & 1.231 & .234 \\
man: has time-limited work contract & .816 & .222 \\
woman: has time-limited work contract & 1.075 & .636 \\
man: has university degree & .646 & .000 \\
woman: has university degree & .566 & .000 \\
Age & 1.293 & .000 \\
Germany & $($ ref.) & $($ ref.) \\
France & 3.718 & .000 \\
Spain & 1.369 & .066 \\
Switzerland & .946 & .764 \\
Poland & 5.523 & .000 \\
Belgium & 4.349 & .000 \\
Constant & .000 & .000 \\
\hline Nagelkerkes $\mathbf{R}^{2}$ & & .401 \\
\hline
\end{tabular}

Data: Job Mobilities and Family Lives in Europe. Couples with respondent aged 25 to 39, not fully agreeing that "it is usually better for the children if the man is the main provider and the woman takes care of the home and the family.” Dependent variable: Couple has children (in our outside the household). Unweighted data.

The limitation of work contracts does not affect the family foundation in a significant statistical way, although the coefficients point to expectable directions and a man's limited contract may have a weak influence. This result is surprising. As argued before, it probably has to be stated that limited work contracts are only one way among others that indicate how jobs can be insecure today, and they may even not always be perceived as insecure if the employee has good reason to expect to receive a new work contract without interruption. In some branches that have limited contracts as a standard, there already may also be an effect of getting used to insecurity and ignoring it in family planning. The flexibility of work hours does not significantly affect the family foundation either. The reasons may be that the flexibility is not always only on the employee's side, although the question was formulated this way, but because it is partly demanded by employers or job responsibilities, or that some employees only have the freedom of choosing which " 23 out of 24 hours" they prefer to work.

Work hours do have a strong and significant effect. However, this is only true in the female partner's job. The man's work hours do not show effects at all. This may reflect 
that the deviation from the standard of a full-time professional career is simply too rare among men to have any statistical explaining power. It certainly also reflects "traditional" gender roles that define that childcare needs a mother, rather than the father, to reduce work. For the same reason, the circumstances in which the female partner has a job or works full-time or even overtime reduces the chance that the couple has children clearly.

Remarkably, job mobility shows clear effects, not only if it occurs in the woman's jobs, but also if it occurs in the man's job. If any of the partners must commute long distances or attend to overnight business travel frequently, then the chance that the couple has children is significantly reduced. For the reasons mentioned above, women's mobility has a stronger effect than the mobility of men. As the effects of other indicators, it can be assumed that a part of this statistical effect is due to a selection effect and indicates a reversed causal relation: Couples with children - or with concrete family plans - will try to avoid job mobility and jobs with many work hours more often and more rigorously than childless couples will. However, the effect, as designed in the regression model, is similarly plausible and certainly also true: Once a couple is confronted with job mobility, it is less likely that they will make or realise family plans soon. Compared to other characteristics of the work situation, job mobility has a strong impact on the compatibility of professional careers and family life. Unlike other aspects, it is perceived as an obstacle for realising parenthood, even for the less challenging father role.

The educational degree works as it was hypothesised and as it is known from the literature: People with academic degrees are less likely to be parents than those without. Additionally to the explanation that rational choice theories give, interpreting education as human capital that increases the opportunity costs for interrupting or reducing professional work, (Becker 1993) it can be assumed that the academic social milieu is more accepting of childlessness than others and socialises women and men to seek self-fulfilment in a professional career.

The dummy variables that measure national differences show highly significant and highly relevant effects. With Germany as a reference, France, Belgium, and especially Poland have a multiplied likelihood that couples have children. Only Spain has a slightly higher likelihood that barely fails to be significant. Switzerland does not deviate from the German pattern. These effects correspond to different overall levels in fertility. ${ }^{5}$ The only clear exception in this comparison is Poland: It shows a higher likelihood of being a parent in the regression analysis although it, meanwhile, has a low total fertility rate. The reason is that couples in Poland, as in most other East European countries, have children at a younger age (OECD Family Database 2008). Therefore, within the cross-sectionally studied age span (with respondents being 25 to 39), there are more parents although the overall fertility is not higher.

There are several macro-level circumstances that cause the national differences. Research has emphasised cultural differences as well as different family policies (Gerhards/ Hölscher 2003; van Oorschot/Opielka/Pfau-Effinger 2008; Weiss 2000; Kaufmann 2002; Lewis/Ostner 1994; Lengerer 2004). West Germany, Austria, Switzerland, and Southern Europe are known to cherish strong social expectations towards the mother role and offer

5 The 2007 total fertility rates are for Germany: 1.37; France: 1.98; Spain: 1.40; Switzerland: 1.46; Poland: 1.31; Belgium: 1.81 (Eurostat 2009). 
little support for parents in terms of public childcare. Scandinavia, France, and Belgium are examples for a more generous support, partly motivated by a strong cultural belief in gender equality; in the French case, it is also motivated by defining higher birth rates as a political goal (Veil 2004). In socialist times, countries in Eastern Europe also had the goal of enhancing birth rates as well as of supporting female labour market participation. This pattern has also been culturally established and partly persists until the present (Hofäcker 2006). The female labour market participation remains high, while births have severely dropped and/or have been postponed to a slightly older age. Both culture and policies are closely linked by reciprocal influences that generally are hard to untangle empirically. Pfau-Effinger has suggested conceptualising the sets of gender culture and gender structure as gender arrangement (Pfau-Effinger 1998). (The age affect is trivial and controlled for in the model only to avoid third variable effects.)

\section{Multivariate analysis, part II: Consequences for women’s job careers}

After the first step in multi-variate analyses of compatibility of job careers and family life, the second step follows. This time, the dependent variable is the question of whether or not the female partner is working for pay. This question allows for different explanatory variables. Attributes of the female partner's job are, of course, only existent under the condition that she has a job at all. They are, in other words, extremely correlated to the dependent variable and therefore cannot be taken into account in the model. Instead, the family situation, which was not part of the previous model for analogue reasons, can now be taken into account. The analysis shows the strength of the resources of time and energy that parenthood requires and the fact that the male partner's job requires the burden of the realisation of a professional career for the woman. Job mobility, as experienced by the male partner, is again tested and compared to the other circumstances' effects.

The overall explanatory power of the model is rather dissatisfying (Nagelkerkes $\mathrm{R}^{2}=.151$ ). This means that the fact of whether or not a female partner in a couple is working for pay is either not strongly affected by any external circumstances, or it is more affected by circumstances that are not included in the model or, likely, the data. However, convincing theoretical arguments about which other circumstances these should be and why are missing. A plausible interpretation, therefore, is that female employment is indeed less affected by the family situation than the family situation is affected by female employment. (Age, which had a very strong impact in the previous model, has no additional explanatory power on this dependent variable and is left out of the model.) Nevertheless, even if more variance remains unexplained, there are effects that are documented in the standardised regression coefficients. Some of them are surprising in their direction. 
Table 2: Circumstances fostering partnered women’s paid work (logistic regression)

\begin{tabular}{lcc}
\hline & Exp(B) & Sig. \\
\hline man: is working for pay & 1.960 & .013 \\
man: is working full-time (35h or more) & .113 & .554 \\
man: is working overtime (45h or more) & .724 & .012 \\
man: is recurringly mobile for the job & 1.005 & .967 \\
man: can choose work hours freely & 1.275 & .111 \\
man: has time-limited work contract & .541 & .000 \\
man: has university degree & .817 & .125 \\
woman: has university degree & 2.388 & .000 \\
couple has children & .670 & .092 \\
number of children & .802 & .003 \\
couple has children under age 6 & .411 & .000 \\
couple receives support for childcare or housework & .000 \\
Germany (ref.) & 2.491 & - \\
France & - & .036 \\
Spain & 1.471 & .403 \\
Switzerland & .188 \\
Boland & 1.154 & .207 \\
Constant & 1.278 & .000 \\
\hline
\end{tabular}

Nagelkerkes $\mathbf{R}^{2}$ .151

Data: Job Mobilities and Family Lives in Europe. Couples with respondent aged 25 to 39, not fully agreeing that "it is usually better for the children if the man is the main provider and the woman takes care of the home and the family." Dependent variable: Woman is working for pay (full-time or part-time). Unweighted data.

If the male partner is working for pay, the chance rises that the female partner has a job. But if he works more than 44 hours a week, the chance decreases. It is plausible that a man can invest work hours beyond a common 40 hours per week in his professional job more easily if he has a housewife who frees him from any household or childcare responsibilities. So, it is plausible that there are reciprocal causal influences between a man working overtime and his female partner working at all and that both may be negotiated by the couple together. In the rare event that the man is not working for pay at all, it would be plausible that the woman compensates his missing contribution to the household income with paid work. Statistically, the opposite is true: If he doesn't have a job, she tends not to have a job either. This correlation may be due to a selection effect, for example, based on student couples in which both partners are not yet in the labour market. It may also reflect the known tendency of homogamy that couples are less stable if partners have different socio-economic backgrounds, especially if the female partner has a higher social position than the man (Lenz 2009).

It is also surprising that the woman's likelihood to have a job decreases if the male partner's job is based on a time-limited contract. Again, one could assume that an insecure income on the man's side should be a reason why the woman should also provide an income. And, again, similar selection effects might explain why this is, at least in a statistically measurable way, not the case. The question of whether or not the man can choose his work hours freely does not have an effect at all - just like in the previous model. 
The influence of the family situation appears to be quite plausible. Whether or not the couple has children as such does not significantly reduce the woman's likelihood to have a job. But the effect is close to being significant. And, for the presence of young children up to the age of five, the effect is highly significant and highly relevant. Also, with a higher number of children it becomes less probable that the female partner is working for pay. Summarising, these numbers can be interpreted in a way that the more time and energy that have to be invested by a couple into childcare, which is typically provided by women, the less likely it is that the female partner still has enough time and energy left to also pursue a professional career of her own. The fourth number also fits into this picture: If the couple receives external support by sending children to a kindergarten, by having a housekeeper or a nanny, by receiving childcare from friends or grandparents, then the woman's chance to work for pay multiplies. This support, as mentioned earlier, may also be the consequence, rather than the cause, of the woman's engagement in the labour market.

What is surprising, but consistent with the bi-variate analyses, is the fact that a male partner's job mobility does not affect the employment of his female partner. For the same reason why a man working 45 hours or more a week decreases his partner's chance of being engaged in the labour market, it would also be plausible that a job-mobile man is more likely to have a housewife without a professional career than a man who returns home from work within a couple of minutes each evening. This is not the case. Again, one explanation is a selection effect: As mentioned before, dual-earner couples have a higher chance to be confronted with job mobility than single-earner couples (cp. Collet/Bonnet in this issue). But, nevertheless, it is remarkable that there is not also an effect in terms of reducing women's engagement on the labour market that would outweigh this selection effect.

Highly significant and plausible is the effect of women's education. Those with an academic degree have a multiplied chance of having a job. Again, there is one interpretation, based on human capital, that has already been mentioned and one based on milieuspecific socialisation: It can be assumed that the academic social milieu socialises women to be more demanding in terms of economic independency and self-fulfilment in their own professional careers. Analogously it would be plausible to assume that men with university degrees are socialised to be more sensitive and supportive for women's interests. The fact that the male partner's educational degree does not have an effect at all on the woman's engagement in the labour market questions this theoretical perspective.

Finally, we see country effects. They become evident in directions that are consistent with the previous model, with France and Belgium fostering female employment more than Germany, Switzerland, or Spain. However, the strength of the effects is much weaker than it was in the previous model. All in all, it seems that couples react to external circumstances and incompatibility, rather with compromises in family planning and family foundation, than with compromises in the female partner's labour market engagement.

\section{Support from the respondents' subjective evaluation}

The data also allow measurement of the reciprocal interrelations between family and professional work that are captured by the aforementioned regression analyses in another way. The survey includes several questions that ask the respondent to subjectively evalu- 
ate these influences. Respondents without children were asked about several potential jobrelated reasons for their childlessness, including various forms of being job mobile (Figure 3). All respondents were asked whether their duties for childcare and housework burdened the success of their professional careers (Figure 4). These evaluations contain all of the advantages and disadvantages that subjective indicators always have: On the one hand, they may be biased by the subjective perception of the respondent and by reactivity; on the other hand, they are free of third variable effects that may not be controlled for in a regression analysis. The subjective indicators may not be a good alternative to multivariate analyses of objective indicators; however, they are a very valuable supplement. If they confirm the results of the regression analyses above, then they crucially increase the reliability of these results.

Figure 3: Subjective evaluation of the reasons for childlessness
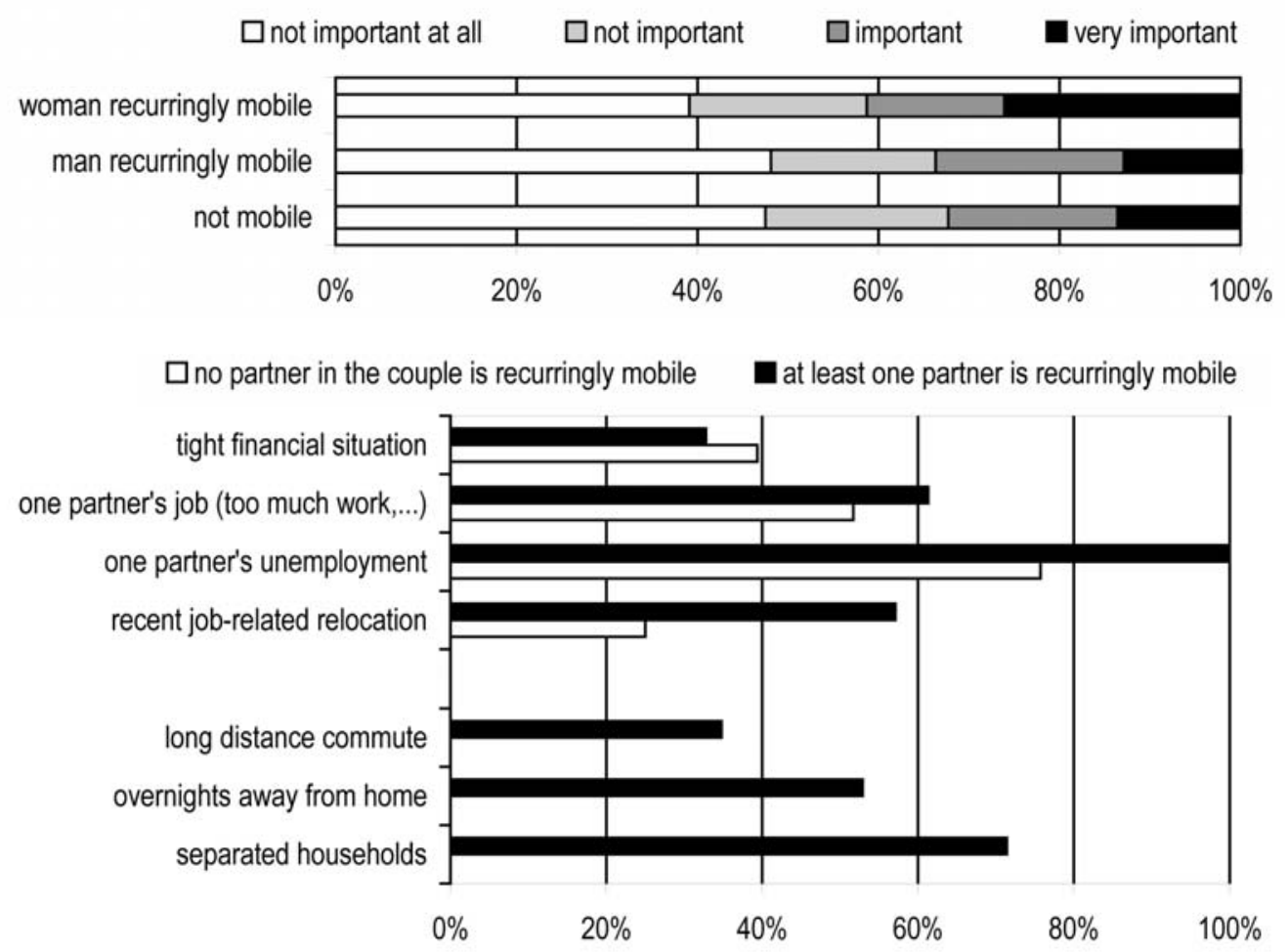

Data: Job Mobilities and Family Lives in Europe. Upper figure: Childless couples with respondent aged 25 to 39. Comparison of couples in which neither partner, the man, or the woman is recurringly mobile for job-related reasons. The residual category (i.e., both partners are recurringly mobile) has been excluded from the analysis. Lower figure: Childless couples with respondent aged 25 to 39 who states that the job-related reasons were "not important at all” for the reason why they don't have children. Weighted data (w-proportion).

The first indicator in Figure 3 confirms the gender difference in the effects of job requirements on family foundation. Job-mobile men and women with mobile partners do 
not have a higher tendency to perceive job-related reasons as important for the fact that they do not have children. Mobile women and men with a mobile partner do. The share of those who evaluate this influence as "very important" almost doubles from $14 \%$ to $26 \%$. This supports the interpretation that, under the condition of persisting gender roles, the hours that are taken away from the female partner by job requirements have more severe consequences for the realisation of family plans than the hours that the male partner invests in his job career.

The set of further indicators in Figure 3, which measure the evaluation of specific characteristics of the job situation, confirms two additional results. The indicator "one partner's job" is actually the aggregation of two indicators in the data set, transferring answers to the couple level. The variable indicates that the respondent has either said "yes" to the question "Is your job a reason - for example, too much work, stress, or responsibility?" or to the equivalent question "Is your partner's job a reason?” Thereby it measures consequences of a high work load of any of the two partners within a couple. More than half of the respondents evaluate the work load as being important. This is consistent with the result from Table 1 that shows that many work hours decrease the chance to become a parent.

Figure 3 also confirms the influence of job mobility. Not only is the work load considered to be more important by people who are personally or through their partners confronted with job mobility than by those who are not. Job mobility itself is also mentioned as being an important cause. The indicators are differentiated by the type of mobility. Living in a long-distance relationship for job-related reasons is most often seen as a reason for not having children. Frequent job-related overnight travel is the second most important cause. Daily long-distance commuting is still relevant but less important. One can summarise that the longer the phases in which job mobility separates the partners spatially, the greater the perception that its consequences for the couple's lack of children are important.

There are some additional insights from the subjective indicators. They reveal that unemployment and financially tight situations can also be reasons not to have children. And they show that a job-related relocation is also sometimes perceived as a reason why the couple has not (yet) founded a family - especially if the relocation experience is in addition to a recurring mobility that the couple also is confronted with.

Figure 4 also confirms a previous result: The professional career seems to be less affected by aggravations of the work-family conflict than the family career. People who have a recurringly mobile partner do not clearly agree more often than others that "Your job career could have been more successful if you had had fewer responsibilities for housework and care-giving." Men disagree with this statement more often than women, which reflects the well-known gender role patterns. A somewhat higher agreement for men with a mobile partner could be concluded from the ratios of full agreement and full disagreement. However, if the variable was dichotomised by putting agreement against disagreement, the opposite tendency would be measured. So these differences need to be interpreted as "white noise" instead of as a correlation. The same is true for the differences in agreement between women with a mobile partner and women with a non-mobile partner. This means that if one partner in a couple becomes recurringly mobile for jobrelated reasons, it does not lead to a cutback in the other partner's professional career, at 
least not in the other partner's subjective perception. Instead, it probably leads to cutting back family plans.

Figure 4: Subjective evaluation of the consequences of childcare duties for one’s own professional career

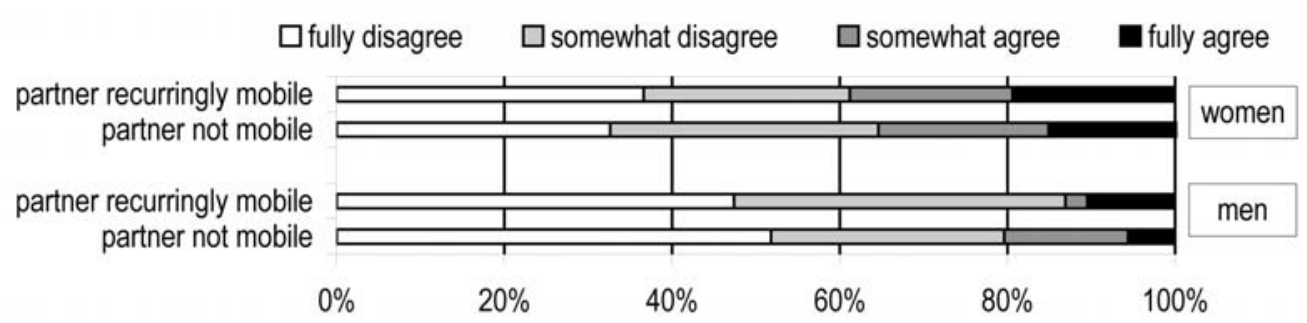

Data: Job Mobilities and Family Lives in Europe. Respondents aged 25 to 39 with a partner. Weighted data (w-proportion).

In summary, it can be stated that the subjective indicators do confirm the main results of the regression analyses: Women's career orientation is not significantly affected by the family situation. The family biography, however, does suffer if the partners' job situations are demanding. Given the persisting gender role patterns, the woman's job situation is crucial in this respect.

\section{Discussion}

It has been argued that, in late modernity and with women's increasing career orientation and refusal of a male breadwinner concept, couples run into increasing challenges of compatibility of professional work and family life. Since both spheres compete for a limited amount of resources in terms of time and energy, it is possible that individuals and couples are unable to invest enough in each sphere to meet all role expectations. This is especially true for the life course phase of early adulthood, in which not only family plans are usually made, but also professional careers are typically established and job mobility is frequent. The consequences may be the failure in realising all goals, in terms of both partners having professional careers and being parents, as analysed in this article. They may also be more subtle, such as having conflicts with the partner or with colleagues. The degree of compatibility is improved or worsened by a variety of circumstances, such as the flexibility of work hours or the availability of childcare support. Among these circumstances, the necessity to be recurringly spatially mobile for the job, such as via longdistance commuting or by taking frequent business trips, etc., is an important issue that has been overlooked in social science research. If it proves to severely aggravate workfamily conflicts, such will be an increasing social problem in the future because job mobility has increased in European societies throughout recent decades.

First of all, the results show that, in general, the relationship between work life and family life is not symmetrical: Family planning and family foundation are more affected 
by the woman's job situation than vice versa. Given that the analyses focus on couples, this observation very likely reflects priorities that the couples make rather than constraints: If two professional careers and parenthood seem to be incompatible, then for most young couples, the two jobs come first. As far as this main priority seems to be achievable at all, the partners probably tend to invest whatever it requires without rational reflection on a daily basis. Whether or not the secondary goal, mostly the family plans, can be achieved in addition is the remaining question that couples perceive as a challenge. Its answer depends on how many resources are left to invest after the primary goal is satisfyingly realised.

There are a number of explanations why couples may define two professional careers as their primary goal instead of becoming parents. Individuals have probably defined this priority before finding a partner and making common plans as a couple. In this situation, a professional career can be pursued through personal effort, whereas realising family plans is dependent on the fortune of finding the "right" partner in time and is, therefore, a risky goal. Certainly, the concern about economic existence is also more fundamental than the wish to have children. And a personal income is a much safer way to secure one's economic existence than relying on finding and keeping a partner who could provide one. A third explanation is the wish to be economically independent within a stable partnership because the (in)dependency affects the relation of power and the gender roles in the couple. Finally, a professional career may seem, to many women and men, to be a more promising way of achieving self-fulfilment and identification than being a full-time mother or father. All in all, rising insecurity in the labour market, rising instability of couple relationships, and processes of value change and individualisation may explain why job orientation today outweighs family orientation - after a historically exceptional phase in the 1950s and 1960s in which this may have been somewhat different (especially for women).

Nevertheless, today there also may be different priorities that define which goal is pursued if several seem to be incompatible. In the analyses, this fact is more reflected in circumstances that are likely to shape these preferences than in the preferences themselves. The educational attainment, for example, affects the likelihood whether the couple has children or whether the woman has a job, partly because people with an academic degree tend to have preferences different from those without. There are other circumstances that influence the preference structure. In any case, knowing the preferences means knowing which goal will be realised if both spheres would require more resources than the couple feels able to invest.

Under the condition that couples do have a principle interest in having two jobs and a family life, several circumstances become relevant that make it more or less likely that these goals can all be reached. Surprisingly, there is no empirical evidence that the freedom of choosing work hours or the limitation of work contracts are among them. Also, the male partner's work hours have no significant influence, whereas the question of whether and how many hours the female partner works for pay is crucial. This means that cultural aspects and subjective preferences come into play as interaction effects another time. As long as men are not thought of as being equally responsible for childcare, their professional situation is not (as) relevant for the couples' perception of being able to realise family plans. 
Compared to other aspects of the job situation, recurring job mobility has strong effects on the work-family conflict. However, as for other aspects, it cannot be stated that it necessarily aggravates it in all cases. It clearly reduces the statistical chance of having a family, but job mobility of one partner does not decrease the chance that the other partner is working for pay. This probably partly reflects a selection effect that job mobiles tend to recruit themselves among rather job-oriented people. Mobile couples will, therefore, rather cut back on the family investment than the career investment if two goals are incompatible - just as other job oriented people would do. In other words, if they have to make choices, they tend to make career-oriented choices more often than non-mobile couples, but they do not necessarily have to make more choices. Another influence comes into play: Couples may become mobile because they want to combine two professional careers and parenthood. For example, a parent may take on a job with a distant workplace and a very long daily commute, and not relocate, so that the children do not lose their friends and do not need to change schools.

The analyses here have concentrated on only two major aspects of combining professional careers with family life. As argued before, there are several more that merit attention by further research. One of them is analysed by Viry, Widmer, and Kaufmann (in this issue): Under certain circumstances regarding the process of how a couple becomes mobile, mobility may burden the partnership quality. Job mobility as such does not have this effect. Therefore, there is little evidence that the lack of time of a mobile partner as such and his inability to invest more into couple or family life provokes partner conflicts or separations. Also, Gerardo Meil's results on this issue are relevant to the question that is raised here: They show that job mobility not only prevents family formation, but it may also reduce the number of children. And, more often, it only postpones births.

The analyses presented here are limited by data and space. The causal influences that lie behind the country effects deserve more attention in the future. Also, the direction and mechanisms of causal influences on the couple level could be studied in a better way as soon as suitable data are available. The analyses in this article are a cross-sectional attempt to capture complex reciprocal causal relationships. They could be studied more adequately with longitudinal data within a couple career perspective.

\section{References}

Andersson, G. (2003). Dissolution of unions in Europe. A comparative overview. MPIDR Working Paper 2003-004. www.demogr.mpg.de/papers/working/wp-2003-004.pdf.

Becker, G. S. (1993): A treatise on the family. Cambridge/Massachusetts: Harvard University Press.

Blossfeld, H.-P., Hofäcker, D., Hofmeister, H. \&. Kurz, K. (2008). Globalisierung, Flexibilisierung und der Wandel von Lebensläufen in modernen Gesellschaften. In: M. Szydli (Ed.), Flexibilisierung: Folgen für Arbeit und Familie. Wiesbaden: VS, pp. 23-46.

Coleman, J. S. (1986). Social theory, social research, and a theory of action. American Journal of Sociology, 91,(6), pp. 1309-1335.

Crompton, R, \& Lyonette, C. (2006). Work-life 'balance’ in Europe. Acta Sociologica, 49, (4), pp. 379-393.

Dorbritz, J. (2000). Europäische Fertilitätsmuster. Zeitschrift für Bevölkerungswissenschaft, 25, (2), pp. 235-266.

Eurostat (2009). The EU-27 population continues to grow. Data in focus No. 31/2009. http://epp.eurostat. ec.europa.eu/cache/ITY_OFFPUB/KS-QA-09-031/EN/KS-QA-09-031-EN.PDF. 
Frejka, T. \& Sobotka, T. (2008). Fertility in Europe. Diverse, delayed and below replacement. Demographic Research, 19, (3), pp. 15-46.

Gareis, K. C., Barnett, R. C, \& Brennan, R. T. (2003). Individual and crossover effects of work schedule fit: A within-couple analysis. Journal of Marriage and Family, 65, (4), pp. 1041-1054.

Gerhards, J. \& Hölscher, M. (2003). Kulturelle Unterschiede zwischen Mitglieds- und Beitrittsländern. Das Beispiel Familien- und Gleichberechtigungsvorstellungen. Zeitschrift für Soziologie, 32,(3), pp. 206-225.

Gestrich, A. (2003): Neuzeit. In: A. Gestrich, J.-U. Krause \& M. Mitterauer (Eds), Geschichte der Familie. Stuttgart: Kröner, pp. 364-405.

Gestrich, A. (2008). Sozialgeschichte der Familie in der Neuzeit. In: N. F. Schneider (Ed.), Lehrbuch Moderne Familiensoziologie: Theorien, Methoden, empirische Befunde. Opladen \& Farmington Hills; MI: Barbara Budrich, pp. 79-98.

Hielscher, V. (2003). Flexible work and work life balance. potential or contradiction. In: G. Bechmann, B.-J. Krings \& M. Rader (Eds), Across the divide: Work, organization and social exclusion in the European information society. Berlin: Edition Sigma, pp. 161-171.

Hill, E. J., Yang, C., Hawkins, A. J. \& Ferris, M. (2004). A cross-cultural test of the work-family interface in 48 countries. Journal of Marriage and Family, 66, (5), pp. 1300-1316.

Hofäcker, D. (2006). Women's employment in times of globalization: A comparative overview. In: H.-P. Blossfeld \& H. Hofmeister (Eds), Globalization, uncertainty and women's careers. An international comparison. Cheltenham: Edward Elgar, pp. 32-58.

Hochschild, A. Russell (1997). The time bind: When work becomes home and home becomes work. Metropolitan Books.

Höpflinger, F. \& Fux, B. (2007). Familien - intereuropäische Perspektive. In: J. Ecarius (Ed.): Handbuch Familie. Wiesbaden: VS, pp. 57-77.

Huinink, J. (2009). Familiale Entwicklungsverläufe und Dynamik in Europa. Ein Überblick. In: O. Kapella, C. Rille-Pfeiffer, M. Rupp \& N. F. Schneider (Eds), Die Vielfalt der Familie. Tagungsband zum 3. Europäischen Fachkongress Familienforschung. Opladen \& Farmington Hills, MI: Barbara Budrich, pp. 347-364.

Huynen, P., Hubert, M. \& Lück, D. (2010). Research design. In: N. F. Schneider \& B. Collet (Eds), Mobile living across Europe. Volume II. Causes and consequences of job-related spatial mobility in cross-national perspective. Opladen \& Farmington Hills, MI: Barbara Budrich, pp. 23-34.

Huynen, P., Montulet, B., Hubert, M., Lück, D. \& Orain, R. (2008). Survey design and methods. In: N. F. Schneider \& G. Meil (Ed.), Mobile living across Europe. Volume I. Relevance and diversity of job-related spatial mobility in six European countries. Opladen \& Farmington Hills, MI: Barbara Budrich, pp. 47-63.

Kaufmann, F.-X. (2002). Politics and policies towards the family in Europe: A framework and an inquiry into their differences and convergences. In: F.-X. Kaufmann, A. Kuijsten, H.-J. Schulze \& K. P. Strohmeier (Eds), Family Life and Family Policies in Europe. Volume 2, pp. 419-477.

Lengerer, A. (2004). Familienpolitische Regimetypen in Europa und ihre Bedeutung für den Wandel der Familie. Zeitschrift für Bevölkerungswissenschaft, 29, (1), pp. 99-121.

Lenz, K. (2009). Soziologie der Zweierbeziehung. Eine Einführung. Wiesbaden: VS.

Lewis, J. \& Ostner, I. (1994): Gender and the evolution of European social policies. Bremen: Universität Bremen, Zentrum für Sozialpolitik (ZeS-Arbeitspapier, No. 4/94).

Lück, D. (2009). Der zögernde Abschied vom Patriarchat. Der Wandel von Geschlechterrollen im internationalen Vergleich. Berlin: Edition Sigma.

Lück, D. \& Hofäcker, D. (2008). The values of work and care among women in modern societies. In: W. van Oorschot, M. Opielka \& B. Pfau-Effinger (Eds), Culture and welfare state. Values of social policy from a comparative perspective. Cheltenham \& Northampton: Edward Elgar, pp. 289-313.

Lück, D. \& Ruppenthal, S. (2010). Insights into mobile living: Spread, appearances and characteristics. In: N. F. Schneider \& B. Collet (Eds): Mobile living across Europe. Volume II. Causes and consequences of job-related spatial mobility in cross-national perspective. Opladen \& Farmington Hills, MI: Barbara Budrich, pp. 35-67. 
Maume, D. J. (2006). Gender differences in restricting work efforts because of family responsibilities. Journal of Marriage and Family, 68, (4), pp. 859-869.

Mitterauer, M. \& Sieder, R. (1984). Vom Patriarchat zur Partnerschaft. Zum Strukturwandel der Familie. München: Beck.

OECD Family Database (2008). SF5: Age of mother at first child's birth. Available at http://www.oecd. org/els/social/family/database/

OECD Family Database (2009). SF7. Childlessness. Available at http://www.oecd.org/els/social/family/ database/

Pfau-Effinger, B. (1998). Gender cultures and the gender arrangement - A theoretical framework for cross-national comparisons on gender. Innovation: the European Journal of Social Sciences, 11, (2), pp. $147-166$.

Reynolds, J. (2005). In the face of conflict: Work-life conflict and desired work hour adjustment. Journal of Marriage and Family, 67, (5), pp. 1313-1331.

Schneider, N. F. (2002). Kindeswohl - Zum Wohl des Kindes? Soziologische Betrachtungen über den Wandel der Elternrolle und die vornehme Zurückhaltung der Gesellschaft bei der Förderung des Kindeswohls. Kind-Prax, 5, pp. 147-152.

Schieman, S., McBrier, D. Branch \& Van Gundy, K. (2008). Home-to-work conflict, work qualities, and emotional distress. Sociological Forum, 18, (1), pp. 137-164.

Schieman, S. \& Glavin, P. (2008). Trouble at the border? Gender, flexibility at work, and the work-home interface. Social Problems, 55, (4), pp. 590-611.

Schulz, F. \& Blossfeld, H.-P. (2006). Wie verändert sich die häusliche Arbeitsteilung im Eheverlauf? Eine Längsschnittstudie der ersten 14 Ehejahre in Westdeutschland. Kölner Zeitschrift für Soziologie und Sozialpsychologie, 58, (1), pp. 23-49.

van Oorschot, W., Opielka, M. \& Pfau-Effinger, B. (2008). Culture and welfare state. Values and social policy in comparative perspective. Cheltenham: Edward Elgar.

Veil, Mechthild (2004). Frankreich. Erklärt die gesellschaftliche Verankerung französischer Familienpolitik die steigenden Geburtenraten und die hohe Müttererwerbstätigkeit? in: Auslandsinfo der Konrad-Adenauer-Stiftung, 1/2004, pp. 4-25.

Voydanoff, Patricia (2004). The effects of work demands and ressources on work-to-family conflict and facilitation. Journal of Marriage and Family, 66, (2), pp. 398-412.

Weiss, D. (2000). The European Union and the family: Law and policy. In: A. Pfenning \& T. Bahle (Eds), Families and family policies in Europe. Comparative perspectives. Frankfurt am Main: Peter Lang, pp. 127-140.

Submitted on/Eingereicht am: 26.04.2010

Accepted on/Angenommen am: 02.07.2010

Address of the author/Anschrift des Autors:

Dr. Detlev Lück

Johannes Gutenberg-Universität Mainz

FB 02, Institut für Soziologie

Colonel-Kleinmann-Weg 2

55099 Mainz

Germany/Deutschland

E-mail:detlev.lueck@uni-mainz.de 